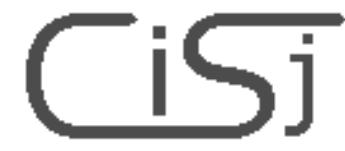

computing@tanet.edu.te.ua www.tanet.edu.te.ua/computing
ISSN 1727-6209

International Scientific

Journal of Computing

\title{
INCREASING ION SELECTIVE ELECTRODES PERFORMANCE USING NEURAL NETWORKS
}

\author{
O. Postolache ${ }^{1,2}$, P. Girão ${ }^{2}$, M. Pereira ${ }^{1}$, Helena Ramos ${ }^{2}$ \\ 1.Escola Superior de Tecnologia, Instituto Politécnico de Setúbal, 2910 Setúbal, Portugal, \\ 2. Instituto de Telecomunicações, DEEC, IST, Av. Rovisco Pais, 1049-001, Lisboa, Portugal \\ E-mails: poctav@alfa.ist.utl.pt, psgirao@alfa.ist.utl.pt, joseper@est.ips.pt,hgramos@alfa.ist.utl.pt
}

\begin{abstract}
This paper reports the implementation of a neural processing structure as a component of an intelligent measuring system that uses ion selective electrodes (ISEs) as sensing elements of heavy metal ions $(P b+2, C d+2)$ concentration. The neural network (NN), designed and implemented to reduce errors due to ion interference and to $\mathrm{pH}$ and temperature variations, is of the multiple-input multiple-output Multilayer Percepton (MLP-NN) type. The NN is a component of a virtual instrument that includes a PC laptop, a PCMCI data acquisition board with associated conditioning circuits and the specific ISE sensors. A practical approach concerning the optimal neural processing solution (number of NN structures, number of neurons, neuron transfer functions) to increase the performance of low cost ISEs is presented. Results are presented to evaluate the performance of the NN intelligent ISE system and to discuss the possibility of transferring the acquisition and processing task to a low cost acquisition and control unit such as a microcontroller.
\end{abstract}

Keywords: intelligent measuring systems, signal conditioning, neural networks.

\section{INTRODUCTION}

Ions of heavy metals, such as lead and cadmium, are an undesired presence in river waters. The monitoring of its concentration requires the utilization of measuring systems often based on ion selective sensors (ISE). Glass electrodes ISEs are characterized by fragility, temperature dependent sensitivity and limited selectivity [1]. All these limitations make their use unsuitable for permanent field measurements required for continuous river water quality monitoring. Other groups of ISEs are solid-state crystal membrane sensors, such as NASICON, and PVC membranes, such as ELIT, which detect the ions (i.e. $\mathrm{Pb}^{+2}, \mathrm{Cd}^{+2}$, $\mathrm{Hg}^{+2}$ ) in aqueous solutions [2][3].

These types of ISEs are robust enough to permit its field utilization. However, most of them have ionselective membranes that allow transit of more than one type of ions. Methods to increase the selectivity of this type of sensors are reported in the literature and are based on multivariable modeling techniques applied to reduce the interference effects. Solutions in the multivariable modeling area use both the fuzzy system [4] and neural networks [5][6] to perform the modeling of sensor with non-linear characteristics and multiple influence factors.

\section{ISE SYSTEM: ISE PRESENTATION AND MODELING}

The present work proposes a ISE $\mathrm{pH}$ and temperature sensor based unit that includes an intelligent processing of sensors information in order to measure the lead and cadmium ions concentration with better accuracy, reducing the errors caused by temperature, $\mathrm{pH}$ variation and ion interference ions. The data sensor fusion based on NNs [7][8] is the main technique used in the present case.

Ion sensing part of the system includes an ISE for lead ions, an ISE for cadmium ions and a reference electrode.

The potential of lead and cadmium ISEs depends on the $\mathrm{Pb}^{+2}$ and $\mathrm{Cd}^{+2}$, respectively, and is given by Nernst equation:

$$
\mathrm{E}=\mathrm{E}_{0}+\frac{2.3 \cdot \mathrm{R} \cdot \mathrm{T}}{\mathrm{Z} \cdot \mathrm{F}} \cdot \log \left(\mathrm{a}_{\mathrm{X}}\right)
$$


where: $\mathrm{E}_{0}$ - reference electrode potential, $\mathrm{R}$ - constant of gases, $\mathrm{T}$ - absolute temperature, $\mathrm{Z}$ - charge on the ion with sign, $\mathrm{F}$ - Faraday constant, ax - activity of the measured ion, $\mathrm{X}$.

Due to the dependence of $\mathrm{E}$ on temperature, a temperature sensor is included in the system to allow the on-line correction of ISE characteristics with temperature.

The activity of each ISE depends on the concentration of the main ions $\left(\mathrm{Pb}^{+2}\right.$ for $\mathrm{Pb}$-ISE or $\mathrm{Cd}^{2+}$ for Cd-ISE) but also on the presence of other ions in the analyzed medium (i.e. river water). In these conditions the $\mathrm{Pb}$-ISE and Cd-ISE output voltages are expressed by Nikolsky-Eiseman equations:

$$
\begin{aligned}
& \mathrm{E}_{\mathrm{Cd}^{+2}}=\mathrm{E}_{0}+\frac{2.3 \cdot \mathrm{R} \cdot \mathrm{T}}{\mathrm{Z} \cdot \mathrm{F}} \cdot \log \left(\mathrm{a}_{\mathrm{Cd}^{+2}}+\sum \mathrm{k}_{\mathrm{pb}, \mathrm{X}_{\mathrm{i}}}^{\mathrm{pot}} \cdot \mathrm{a}_{\mathrm{x}_{\mathrm{i}} \mathrm{Z}_{\mathrm{i}}}\right) \\
& \mathrm{E}_{\mathrm{Pb}^{+2}}=\mathrm{E}_{0}+\frac{2.3 \cdot \mathrm{R} \cdot \mathrm{T}}{\mathrm{Z} \cdot \mathrm{F}} \cdot \log \left(\mathrm{a}_{\mathrm{Pb}^{+2}}+\sum \mathrm{k}_{\mathrm{cd}, \mathrm{x}_{\mathrm{i}}}^{\mathrm{pot}} \cdot \mathrm{a}_{\mathrm{x}_{\mathrm{i}} \mathrm{Z}_{\mathrm{i}}}\right)
\end{aligned}
$$

where $\mathrm{a}_{\mathrm{Pb}^{+2}} \quad \mathrm{a}_{\mathrm{Cd}^{+2}}$ are the $\mathrm{Pb}^{+2}$ and $\mathrm{Cd}^{+2}$ activities, $\mathrm{k}_{\mathrm{Pb}, \mathrm{X}_{\mathrm{i}}}^{\mathrm{pot}}$ and $\mathrm{k}_{\mathrm{Cd}, \mathrm{X}_{\mathrm{i}}}^{\mathrm{pot}}$ represent the potentiometric selectivity coefficients of the ISE considered electrodes for different interfering ions, $Z_{i}$ are the charge number of the interfering ions and $R$ the constant of gases. The potentiometric selectivity coefficient defines the ability of an ion-selective electrode to distinguish a particular ion from others [9]. Ion activity is proportional to concentration. Thus, in the particular case of $\mathrm{Pb}^{+2}$ and $\mathrm{Cd}^{+2}$, activities are expressed by:

$$
\mathrm{a}_{\mathrm{Pb}^{+2}}=\gamma_{1} \times \mathrm{C}_{\mathrm{Pb}^{+2}} ; \mathrm{a}_{\mathrm{Cd}^{+2}}=\gamma_{2} \cdot \mathrm{C}_{\mathrm{Cd}^{+2}}
$$

where $\gamma_{1}$ and $\gamma_{2}$ are the activity coefficients that depend on the ionic strength of the measured solution and $\mathrm{C}_{\mathrm{Pb}}{ }^{+2}$ and $\mathrm{C}_{\mathrm{Cd}}{ }^{+2}$ are the concentrations of lead and cadmium, respectively.

Taking into account the complexity of ISE sensors, a global characterization using neural networks is a solution to consider.

\section{ISE SYSTEM: HARDWARE}

The ISE sensors are part of a virtual instrument designed and implemented to measure the ion concentration in the river water. Sensors used are ELIT8231 and ELIT8241, specific ISE for $\mathrm{Pb}^{+2}$ and $\mathrm{Cd}^{+2}$, and a double junction lithium acetate ELIT003 as the reference electrode (Fig.1).
Considering that the used sensors are potentiometric, the electrode polarization due to the current should be avoided. For this purpose a conditioning circuit with two $1,2 \mu \mathrm{A}$ Max, singlesupply MAX406 operational amplifiers (AO1 and $\mathrm{AO} 2)$ is implementeded. $\mathrm{AO} 1$ and $\mathrm{AO} 2$ output voltages are acquired using two analog differential inputs $\left(\mathrm{ACH} 0\right.$ and $\mathrm{ACH} 8$ for $\mathrm{V}_{\mathrm{Pb}} \mathrm{ISE}$ and $\mathrm{ACH} 1$ and ACH9 for $\mathrm{V}_{\mathrm{Cd}} \mathrm{ISE}$ ) of a PC notebook plugged-in data acquisition board (PCMCIA DAQ6022).

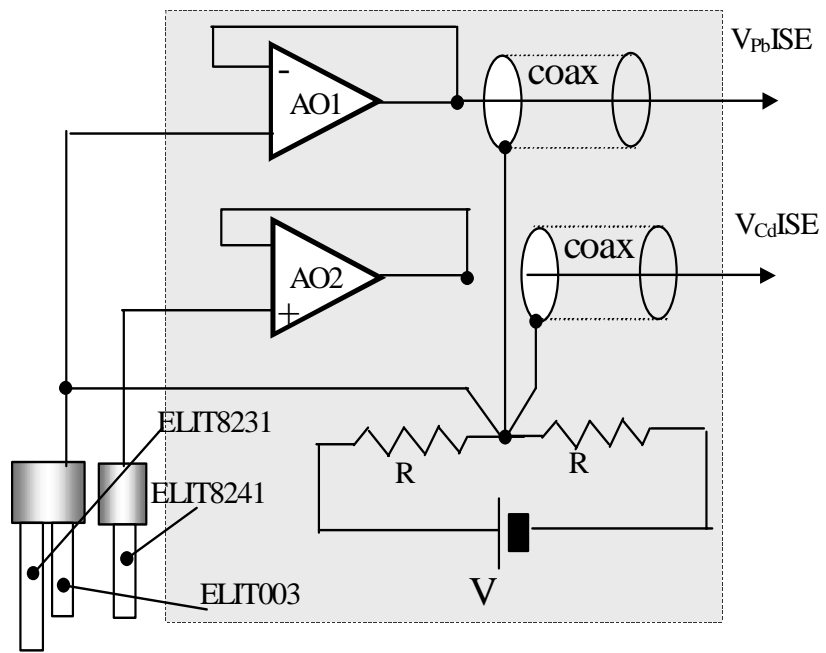

Fig. 1. ISEs conditioning block.

Referring to the temperature conditioning circuit, a LM324 based controlled current source is implemented in order to obtain a voltage signal $\mathrm{V}_{\mathrm{T}}$ linearly dependent on the resistance variations of a ON401 thermistor. The injected current is $0.2 \mathrm{~mA}$ in order to prevent self-heating effects.

The value of concentration's $\mathrm{pH}$ is also an important parameter that influences ISEs output, namely for low values of ion concentrations. Fig. 2 shows the effects of $\mathrm{pH}$ variation on the concentration measurement in the particular case of $\mathrm{Cd}^{+2}$ ion measured with ELIT8241. In the figure, $\mathrm{V}_{\text {ISE_Cd }}$ expresses $\mathrm{Cd}^{+2}$ ion sensor acquired voltage, $\mathrm{pH}$ represents the value of $\mathrm{pH}$ measured with ISI model $11 \mathrm{pH}$ sensor and $\Delta \mathrm{e}_{\mathrm{pXCd}}$ represents the $\mathrm{pX}_{\mathrm{Cd}}{ }^{+2}$ absolute errors obtained for different $\mathrm{pH}$ values. The $\Delta \mathrm{e}_{\mathrm{pXCd}}$ error is defined by the following relation:

$$
\Delta \mathrm{e}_{\mathrm{pXCd}}=\mid \frac{\left.\mathrm{pX}_{\mathrm{Cd}^{+2}}\right|_{\mathrm{pH=pH}}-\mathrm{pX}_{\mathrm{Cd}}+\left.2\right|_{\mathrm{pH}=5}}{\mathrm{pX}_{\mathrm{Cd}}+\left.2\right|_{\mathrm{pH}=5}} \cdot \cdot 100[\%]
$$

where

$$
\mathrm{pX}_{\mathrm{Cd}}{ }^{+2}=-\log _{10}\left(\mathrm{C}_{\mathrm{Cd}^{+2}}\right)
$$




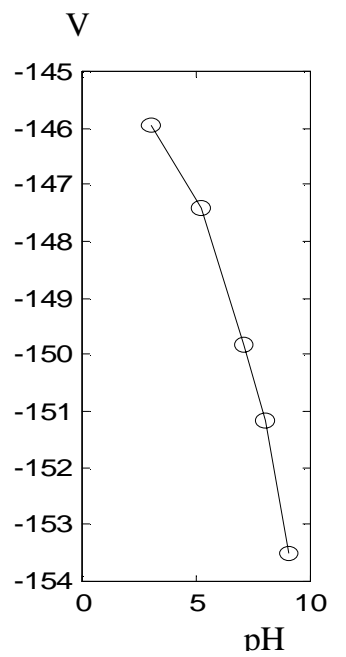

(a)

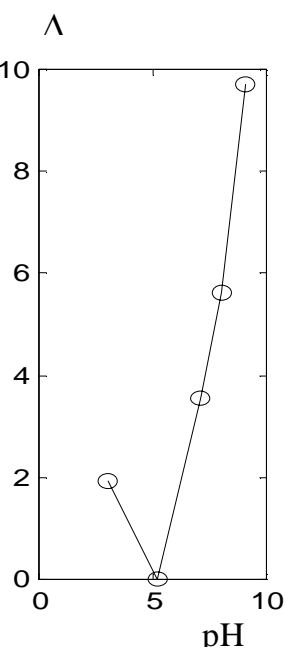

(b)
Fig. 2. pH influence on $\mathbf{C d}+2$ measurement using ELIT8241 sensor $(\mathrm{pH} \in[3,9]$ and $\mathrm{pXCd} \in[4,7]$. (a) sensor's output voltage, VCd-ISE versus $\mathrm{pH}$ for $\mathrm{pXCd}+2=5$; (b) $\mathrm{pX}$ absolute errors versus $\mathrm{pH}$.

Thus, the $\mathrm{pH}$ of the tested solution is measured using the ISI11 $\mathrm{pH}$ transducer that delivers a voltage included in $0-300 \mathrm{mV}$ interval for $\mathrm{pH}=[1-10]$. After conditioning, the voltage signal corresponding to $\mathrm{pH}$ is digitized using the DAQ.

Fig. 3 shows the overall hardware and its interface with the software component of the measuring system.

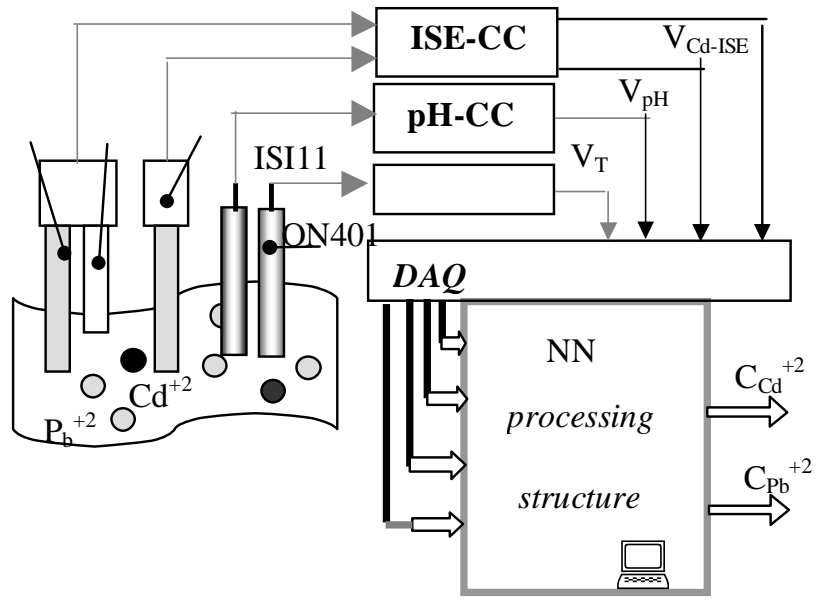

Fig. 3. The ISE based virtual instrument for $\mathrm{Pb2+}$ and $\mathbf{C d}+2$ ion concentration measurement.

\section{ISE SYSTEM: SOFTWARE}

The software components of the virtual system are related with the acquisition and filtering of $\mathrm{V}_{\mathrm{Pb}-\mathrm{ISE}}$, $\mathrm{V}_{\mathrm{Cd}-\mathrm{ISE}}, \mathrm{V}_{\mathrm{pH}}, \mathrm{V}_{\mathrm{T}}$ and with the neural processing of the acquired voltages in order to obtain the accurate values of $\mathrm{Pb}^{+2}$ and $\mathrm{Cd}^{+2}$ ions concentration with compensation of temperature, $\mathrm{pH}$ and interfering ion effects.

Data acquisition and filtering are performed using a set of LabVIEW functions. Acquisition sampling rate is $f_{s}=10 \mathrm{kS} / \mathrm{s}$. For each sampling set corresponding to $\Delta \mathrm{t}_{\mathrm{i}}=1 \mathrm{~s}$ acquisition time, average voltages $\mathrm{V}_{\text {ISE_Cdi }}$ avg. $\mathrm{V}_{\text {ISE_Pbi }}{ }^{\text {avg }}, \mathrm{V}_{\mathrm{Ti}}^{\text {avg. }}, \mathrm{V}_{\mathrm{pHi}}^{\text {avg }}$ are calculated in order to increase the signal to noise ratio (SNR). The time interval between two acquisition times is set at $\tau_{\mathrm{I}}=1$ min. Different $\mathrm{Cd}^{+2}$ and $\mathrm{Pb}^{+2}$ based solutions ( $\mathrm{C}_{\mathrm{Cd}}{ }^{+2}$ and $\left.\mathrm{C}_{\mathrm{Pb}}{ }^{+2}=[0.14 ; 10] \mathrm{ppm}\right)$ with different $\mathrm{pH}$ $(3 \div 9)$ values and temperature $(\mathrm{T}=[273-303] \mathrm{K})$ are considered in order to obtain the corresponding sensor voltage responses used to train and test the neural network (NN) processing structure design. The main blocks included in the NN processing structure are the $\mathrm{NN}$ temperature sensor-processing block (NN-T), the $\mathrm{NN}$ pH sensor-processing block $(\mathrm{NN}-\mathrm{pH})$ and the NNISE processing block (NN-ISE) all of them expressed by multilayer perceptron neural networks (Fig. 4).

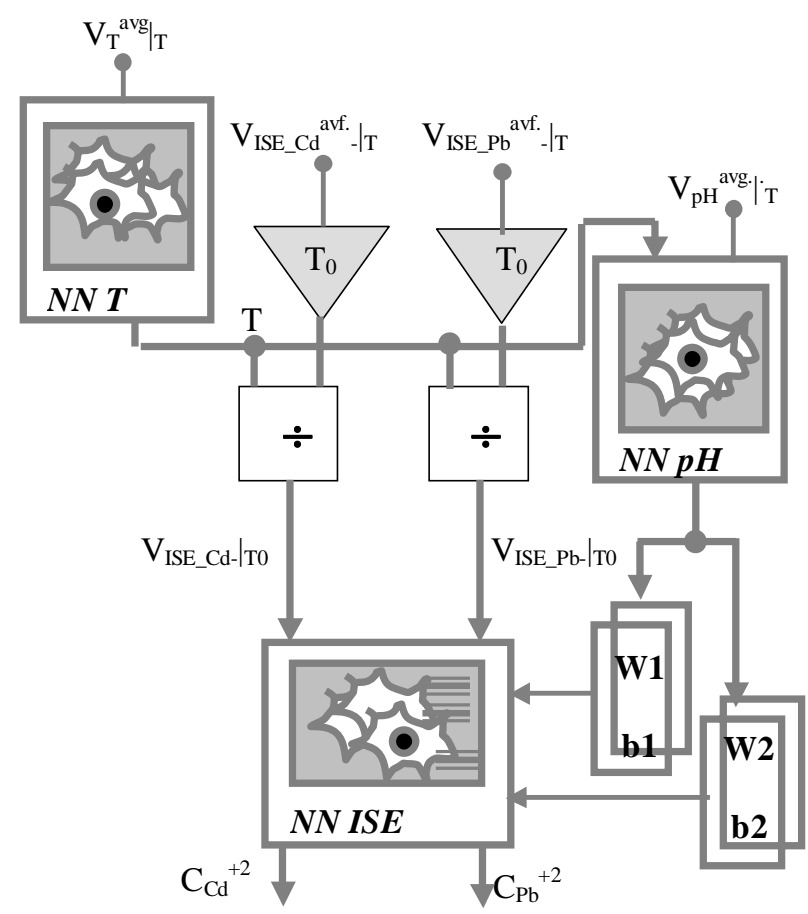

Fig. 4. The NN processing structure.

\subsection{NN temperature sensor processing block}

The NN-T performs temperature (T) calculation of the aqueous solution under test using the $\mathrm{V}_{\mathrm{Ti}}^{\text {avg }}$ acquired 
voltage. The main characteristics of the considered neural networks are:

- $\quad$ type - multilayer perceptron, single input, single output;

- number of layers - 3 layers (input layer, hidden layer, output layer);

- number of neurons - 1 in the input layer, 2 to 10 in the hidden layer, 1 in the output layer;

- neuron transfer functions - linear, for output neurons $\left(f_{\text {output }}\right)$, tansignoid [10], for hidden neurons $\left(\mathrm{f}_{\text {hidden }}\right)$.

The weights (W1, W2) and biases $(\mathrm{b} 1, \mathrm{~b} 2)$ of the $\mathrm{NN}$ are obtained using the Levenberg Marquardt algorithm [11] for an imposed training stop condition expressed by the sum square error value, $\mathrm{SSE}_{\mathrm{STOP}}$. The training and testing sets correspond to 273 to $303 \mathrm{~K}$ temperature interval.

In the training phase a data set including half of the 48 pairs of $\mathrm{V}_{\mathrm{T}}$ and temperature experimentally obtained is used to design the neural network Taking into account the capabilities of the Matlab NN training implemented program, a study concerning the $\mathrm{n}_{\text {hidden }}\left(\mathrm{SSE}_{\mathrm{STOP}}\right)$ characteristic is performed. A graphical expression of the above mentioned characteristic is presented in Fig. 5. As shown in the figure, for $n_{\text {hidden }}>9$ neurons the test error $\left(e_{t}\right)$ defined as:

$$
\mathrm{e}_{\mathrm{t}}=\max \left|\mathrm{o}_{\mathrm{NN}_{\mathrm{i}}}-\mathrm{o}_{\text {test }_{\mathrm{i}}}\right|_{\mathrm{i}=1 . . \mathrm{M}}
$$

where $\mathrm{o}_{\mathrm{NNi}}$ is the $\mathrm{NN}$ output value and the $\mathrm{o}_{\text {testi }}$ represents the test $\mathrm{NN}$ target value is ten times greater than the $e_{t}$ calculated for $2 \leq n_{\text {hidden }} \leq 9$ case. The training stop condition for both situations is $\mathrm{SSE}_{\mathrm{STOP}}=0.005$. Considering as the aim of the NN design the higher accuracy of numerical linearization and, at the same time, the reduction of $\mathrm{NN}$ number of neurons, the possible solutions for temperature linearization are presented in Table 1.

Table 1. NN-T architecture and performances

\begin{tabular}{|l|l|l|}
\hline $\mathrm{n}_{\text {hidden }}$ & $\mathrm{SSE}_{\mathrm{STOP}}$ & $\mathrm{e}_{\mathrm{t}}(\mathrm{K})$ \\
\hline 5 & 0.00005 & 0.13 \\
\hline 6 & 0.0005 & 0.21 \\
\hline 7 & 0.0001 & 0.21 \\
\hline
\end{tabular}

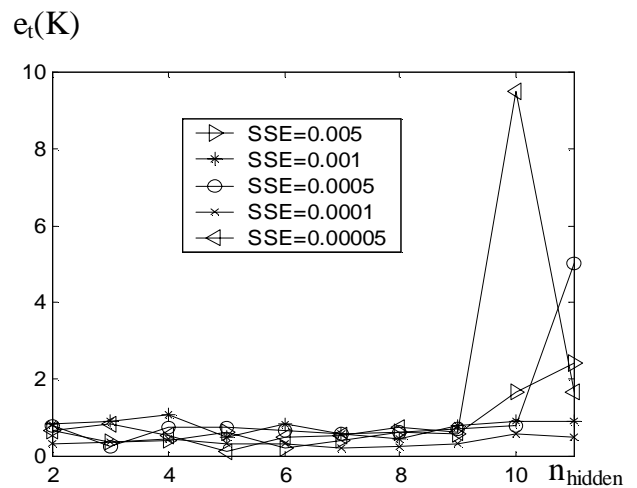

Fig. 5. The evolution of test error et for different NN-T architectures and training stop conditions.

\subsection{NN pH sensor processing block}

Referring to the NN-pH architecture, a two inputs and one output structure is used [12]. Its main characteristics are: (a) number of layers - 3 layers (input layer, hidden layer, output layer); (b) number of neurons - 2 in the input layer (corresponding to $\mathrm{T}$ and $\mathrm{V}_{\mathrm{pH}}^{\text {avg. }}$ ), 10 to 40 tansignoid hidden neurons, 1 linear output neuron.

In the $\mathrm{NN}-\mathrm{pH}$ training phase a $2 \times 20$ input matrix $\left(\mathbf{P}_{\mathbf{p H}}\right)$, including the normalised values of temperature and $\mathrm{V}_{\mathrm{pH}}$, and $1 \times 20$ target matrix $\left(\mathbf{T}_{\mathbf{p H}}\right)$, including the temperature compensated $\mathrm{pH}$ normalised values, are used. The network is trained using the LevenbergMarquardt algorithm and a stop condition expressed by $\mathrm{SSE}_{\mathrm{STOP}} \leq 1 \mathrm{E}-4$.

Results of the network testing for different number of neurons in the hidden layer are summarized in Fig. 6. Analysing the figure it can be underlined that the best approximation of $2 \mathrm{D} \mathrm{pH}$ characteristics is obtained for $\mathrm{n}_{\text {hidden }}=45$ and the corresponding weights and biases are implemented in LabVIEW for on line extraction of temperature compensated $\mathrm{pH}$ value.

\subsection{NN ISE processing block}

After having the temperature and the temperature corrected $\mathrm{pH}$ values, the first natural solution to obtain the concentration of metals taking into account not only those two quantities but also ion cross interference on sensors output voltage using a neural network, is to convert sensors voltage from temperature $\mathrm{T}$ to temperature $\mathrm{T}_{0}$ at which data is obtained in laboratory and then to implement a three input, two output neural network whose inputs are those converted values and the temperature corrected $\mathrm{pH}$ value and whose outputs are metal concentrations. 
This solution is not however considered. In fact, the problem faced of finding a 2 dimensional solution in a 3 dimensional space using neural networks is only well or fairly solved if the network is trained using a large set of input values, that is to say, if the region of training finely covers the region where solutions are. In the absence of such a set, and similarly to the NN $\mathrm{pH}$ sensor-processing block, the NN ISE processing block uses a two input single output multilayer perceptron but whose weights and biases are a function of the temperature corrected $\mathrm{pH}$ value (Fig. 4). The main characteristics of the network are:

- type - two-inputs-two outputs multilayer percepton;

- number of layers - 3 layers (input layer, hidden layer, output layer);

- number of neurons - 2 in the input layer (corresponding to the voltage acquired on the temperature channel, 10 to 50 tansignoid neurons in the hidden layer, 2 linear on the output layer.

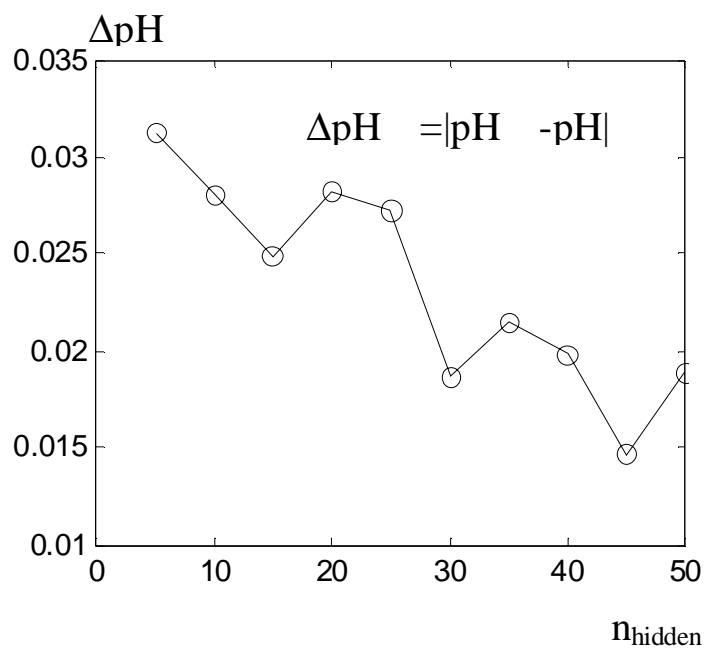

Fig.6. The evolution of $\triangle \mathrm{pHNN}$ versus number of neurons of the $\mathrm{NN}$-pH hidden layer.

The neural network training set is composed by several pairs of input $\mathbf{P}_{\mathbf{I S E}}{ }^{\mathbf{p H i}}(2 \times 36)$ and target $\mathbf{T}_{\mathbf{I S E}}{ }^{\mathbf{p H i}}$ $(2 \times 36)$ matrices each pair corresponding to a $\mathrm{pH}$ value $\left(\mathrm{pH}_{\mathrm{i}}\right)$ of the ISEs calibration solution. $\mathbf{P}_{\mathbf{I S E}}{ }^{\mathbf{p H i}}$ includes the pairs of $\mathrm{V}_{\mathrm{Cd} \_ \text {ISE }}$ To and $\mathrm{V}_{\mathrm{Pb} \_ \text {ISE|To }}$ values acquired from the ISE channels in the laboratory conditions $\left(\mathrm{T}_{0}\right)$ and ISE calibration phase. The target matrix is expressed by the concentration of the $\mathrm{Cd}^{+2}$ and $\mathrm{Pb}^{+2}$ ions in the measured solution. In order to reduce errors, the NN-ISE is designed using voltages and ion concentration values corresponding to two ion concentration ranges, $\mathrm{C}_{\mathrm{Cd}^{+2}}, \mathrm{CPb}^{+2} \in[0.14 ; 1] \mathrm{ppm}$, $\mathrm{C}_{\mathrm{Cd}}{ }^{+2}, \mathrm{CPb}^{+2} \in[0.14: 10] \mathrm{ppm}$.
The designed NN-ISE operates with the $\mathrm{V}_{\text {Cd_ISE|To }}$ and $\left.\mathrm{V}_{\mathrm{Pb} \_ \text {ISE }}\right|_{\mathrm{T}}$ obtained from the measured $\mathrm{V}_{\mathrm{Cd} \_ \text {ISE }}$ and $\left.\mathrm{V}_{\mathrm{Pb} \_\mathrm{ISE}}\right|_{\mathrm{T}} \mathrm{u}$ sing the following relations.

$$
\begin{aligned}
& \left.\mathrm{V}_{\text {ISE_Cd }}\right|_{\mathrm{T}_{0}}=\left.\mathrm{V}_{\text {ISE_Cd }}\right|_{\mathrm{T}} \cdot \frac{\mathrm{T}_{0}}{\mathrm{~T}} \\
& \left.\mathrm{~V}_{\text {ISE_Pb }}\right|_{\mathrm{T}_{0}}=\left.\mathrm{V}_{\text {ISE_Pb }_{-} \mathrm{Pb}}\right|_{\mathrm{T}} \cdot \frac{\mathrm{T}_{0}}{\mathrm{~T}}
\end{aligned}
$$

where $\mathrm{T}$ represents the temperature of the measured solution and $\mathrm{T}_{0}$ is the temperature at which training and testing values are obtained

The used training algorithm is Levenberg Marquardt and the stop condition is $\mathrm{SSE}_{\mathrm{STOP}}=0.001$. In order to obtain an optimal solution in terms of ISE characteristics modeling accuracy, different NNs with different number of hidden neurons are trained and tested, the final structure being represented by 2 input neurons, 20 tansignoid-hidden neurons and 2 linear output neurons.

\section{RESULTS AND DISCUSSION}

After the NNs are designed in Matlab, on line data processing is fully implemented in LabVIEW. Thus, weights and biases of NN-T, NN-pH and NN-ISE stored in files are directly accessed according to the acquired voltage on the T, pH, ISE_Cd and ISE_Pb channels and used as factors and terms involved in matrices multiplication that lead to $\mathrm{C}_{\mathrm{Cd}}{ }^{+2}$ and $\mathrm{C}_{\mathrm{Pb}}{ }^{+2}$ values.

The designed neural network based system is tested on-line for different solutions characterized by different concentrations of $\mathrm{Cd}^{+2}$ and $\mathrm{Pb}^{+2}$ ions included in $[0.1 ; 1] \mathrm{ppm}$ and $[0.1 ; 10] \mathrm{ppm}$. The temperature and $\mathrm{pH}$ of the tested solutions correspond to typical river water conditions: $\mathrm{pH}=5.2$ and $\mathrm{T}=293 \mathrm{~K}$. Results are presented in Fig.7 and Fig.8 and reveal the concentration absolute errors are smaller than 0.01 ppm for the 0 to $1 \mathrm{ppm}$ scale and $0.1 \mathrm{ppm}$ for 0 to 10 ppm scale that, which represent less than $1 \%$ of full scale in both cases.

In order to evaluate the advantage of the $\mathrm{NN}$ utilization in the presented application, errors with $\mathrm{NN}$ processing (NN T, NN-pH and NN-ISE) are compared with errors without correction.

Ignoring temperature correction, ion concentration measurement errors are about $6 \%$ when the temperature of the ISE is in the $278 \mathrm{~K}$ to $303 \mathrm{~K}$ interval. Using the above presented temperature scaling technique, and considering that the errors associated with temperature measurement are about 
$0.2 \mathrm{~K}$, system's errors negligible since they are reduced to some $0.05 \%$.

In what concerns $\mathrm{pH}$ and ion interference correction, ELIT sensor manufacturers indicates only that under particular conditions (one single type of ion, $\mathrm{pH}=3-7$, activity coefficient>0.98), the concentration value obtained has an error of some $5 \%$. In our case, only with two ions present and concentrations between 0.1 and 1o ppm, the error of concentration evaluation neglecting interference effects and thus using (1) is much higher reaching some $500 \%$ (for an interference concentration 10 times greater than the primary ion concentration). This fact renders useless this type of sensors in applications where several ions are simultaneously present in the medium under measurement without some sort of post data processing. As can be seen in Fig. 7 and Fig. 8, this error is reduced with the proposed data fusion method to $1 \%$ in the worst case $((0.1 \mathrm{ppm} / 10$ ppm) $\times 100)$,

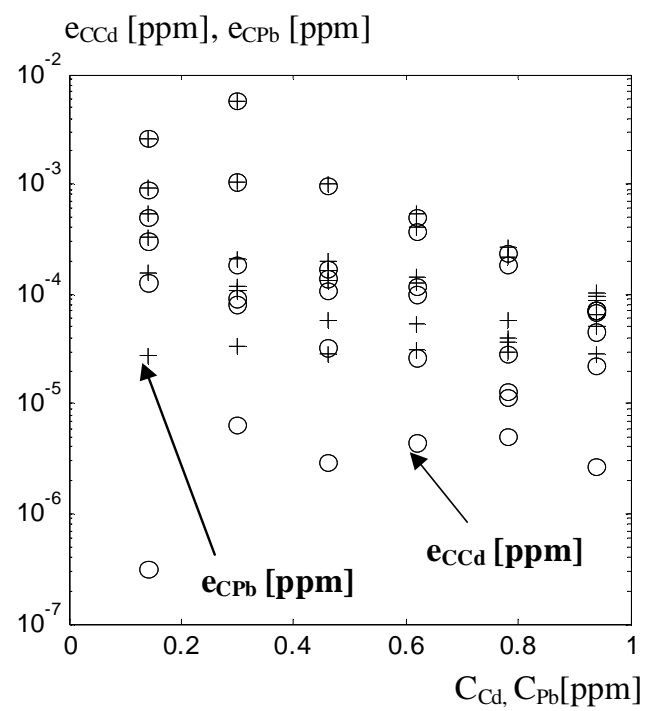

Fig. 7. Concentration error $(\mathrm{eC})$ versus concentration for low concentrations of $\mathrm{Cd}+2$ and $\mathrm{Pb}+2$ ions. $+-\mathrm{Pb}$; o - Cd.

\section{CONCLUSION}

The ISE based system proposed increases the performance of ion selective electrodes used for heavy metal concentration measurement compensating the effects of interfering ions, of temperature and $\mathrm{pH}$ variations using additional sensors and adequate neural processing structures.

In what acquisition of sensors output voltages is concerned, a microcontroller with a 12 bits analog-to- digital converter can be used instead of the PC plugged-in data acquisition board.

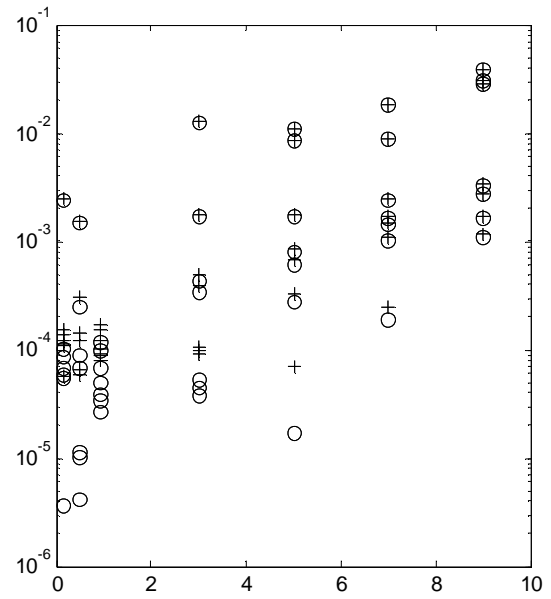

Fig. 8. Concentration error $(\mathrm{eC})$ versus concentration for high concentrations of $\mathrm{Cd}+2$ and $\mathrm{Pb}+2$ ions. $+-\mathrm{Pb}$; o - Cd.

A practical approach concerning the dependencies between the NNs performance and the number of processing units was performed in order to evaluate the relationship between the performance and the NN implementation complexity. The conclusion obtained is that after $\mathrm{NN}$ optimization, the proposed solution can be easily implemented also in a microcontroller. The possibility of microcontroller usage both for data acquisition and processing tasks is very attractive for field measurements and monitoring applications.

Also, the flexibility of the system permits to add new ISEs to the system without important changes of system's hardware and of increase of system's software complexity.

\section{ACKNOWLEDGMENTS}

This work was supported both by Portuguese Science and Technology Foundation PRAXIS XXI program FCT/BPD/2203/99 and by Project FCT PNAT/1999/EEI/15052. These supports are gratefully acknowledged. We also would like to thank Centro de Electrotecnia Teórica e Medidas Eléctricas, IST, Lisboa, for its important technical support.

\section{REFERENCES}

[1] P. Fabry, J. Gros, J. Million-Brodaz, "NASICON, an ionic conductor for solid-state $\mathrm{Na}^{+}$selective electrode", Sensors and Actuators, 15 (1988) 3349. 
[2] P. Fabry, E. Siebert, C. Gondran, A. Attari, H. Khireddine, "De nouvelles céramiques conductrices pour capteurs ioniques potentiométriques", Science Technique Technologie 24, (1993), 30-37

[3] Nico 2000. Ltd-"Operating Instructions for ELIT Ion-selective Electrodes", Nico 2000 Publishing.

[4] M. Heniche, M. Attari, F. Boudjena, "Reducing the effects of temperature and $\mathrm{K}^{+}$activity in sodium measurement by mean of a fuzzy logic system", Proc. IMEKO-TC4, Naples, Italy, (1998), pp.602606.

[5] O. Postolache, P. Girão, M. Pereira, "Neural Network in Automatic Measurement System: State of Art and New Research Trends", Proc. IEEE - IJCNN'2001, Washington DC, vol. 3-4, (2001), pp.2310-2315.

[6] C. Alippi, V. Piuri, F. Scotti, "A Methodology to Solve Performance/Complexity Trade-off in RBF Neural Networks", Proc. IEEE International Workshop on Virtual and Intelligent Measurement System, Annapolis, USA, (2000), 147-150.

[7] L. Jain, N. Martin, Fusion of NN, Fuzzy Sets, and Genetic Algorithms - Industrial Applications, CRC Press, Washington DC, (1998).

[8] David L. Hall and James Llinas (Editors), Handbook of Multisensor Data Fusion, The Electrical Engineering and Applied Signal Processing Series, CRC Press LLC, Boca Raton (FL), (2001).

[9] IUPAC Compendium of Chemical Terminology $2^{\text {nd }}$ Edition 1997

[10] P. V. Venvilainen, H. Ihalainen, "Estimating the Activation Functions of an MLP-Network", Proc. IMEKO World Congress, Vol. IX, pp.359-364, Wien, 2000.

[11] S. Haykin, Neural Networks - A Comprehensive Foundation, Prentice Hall, (1999).

[12] O. Postolache, M. Pereira, P. Girão, M. Cretu and C. Fosalau, "Application of neural structures in water quality measurements", Proc. IMEKO World Congress, Wien, Oct. 2000, vol. IX, pp.353-358.

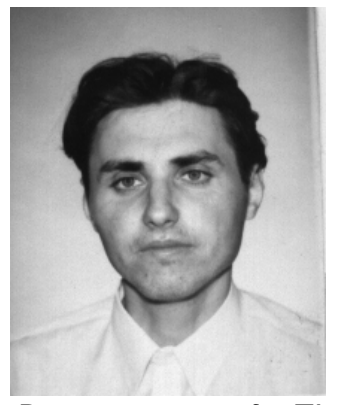

Octavian Postolache (M'99) was born in Piatra Neamt, Romania, on July 29, 1967. He received the electrical engineering diploma from Technical University of lasi, Faculty of Electrical Engineering in 1992. In 1992, he joined the Faculty of Electrical Engineering lasi, Department of Electrical Measurements as an Assistant Professor where he is currently Aux. Prof.. In the last two years he develop a research activity on Instituto Superior Tecnico of Lisbon. His main research interests concern on intelligent sensor, laser systems and neural processing in automated measurement systems.

\section{P.M.B. Silva Girão (M'00,} SM'01) was born in Lisbon, Portugal, on February 27, 1952. He received the Ph.D. degree in electrical engineering from the Instituto Superior Técnico of the Technical University of Lisbon (IST/UTL) in 1988. In 1975, he joined the Department of Electrical

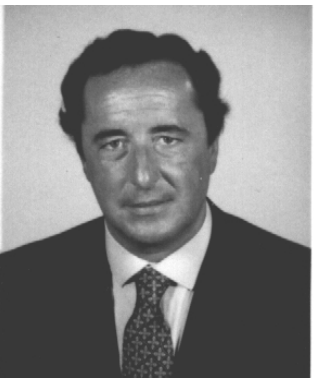

Engineering at IST/UTL, first as an Assistant Professor and, since 1988, as an Associate Professor. His main research interests concern instrumentation, measurement techniques as well as physical and mathematical problems involved in modelling magnetic materials. Metrology, quality and electromagnetic compatibility are also areas of regular activity mainly as auditor for the Portuguese Institute for Quality (IPQ).

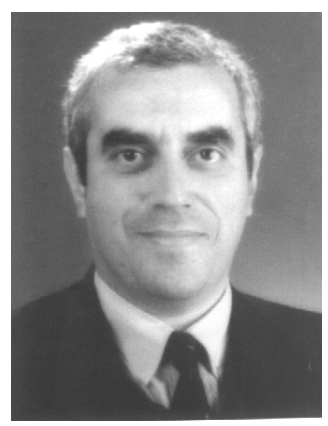

J.M. Dias Pereira (M'02) received his degree in Electrical Engineering from the Instituto Superior Técnico (IST) of the Technical University of Lisbon (UTL) in 1982. He worked for eight years for Portugal Telecom in digital switching and transmission systems. In 1992, he returned to teaching as Assistant Professor in Escola Superior de Tecnologia of Instituto Politécnico de Setúbal, where he is, at present, a Coordinator Professor. In 1995, he received the MSc degree and in 1999 the PhD degree in Electrical Engineering and Computer Science from IST. His main research interests are in the instrumentation and measurements areas. 


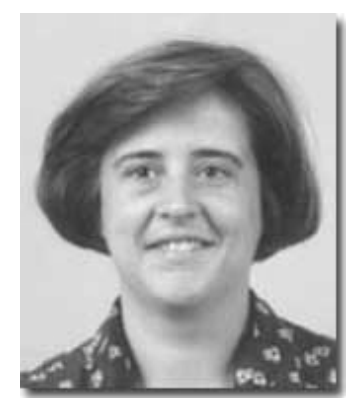

Helena Maria G. Ramos was born in Lisbon, Portugal, on October 18, 1957. She received the M.Sc. and Ph.D. degrees in electrical engineering from the Instituto Superior Técnico of the Technical University of Lisbon (IST/UTL), in 1987 and 1995 respectively. In 1981, she joined the Department of

Electrical Engineering at IST/UTL, first as Assistant and, since 1995, as a Professor. Her main research interests are in the area of instrumentation and measurement techniques. 